\title{
The research and practice of the teaching mode called the Flipped Classroom in the lesson 《Principles of Computer Composition》
}

\author{
Leilei Deng,Zitong Wang ${ }^{1}$, Xian Zhang ${ }^{2, a}$ \\ ${ }^{1}$ Institute of Information and Technology ,Jilin Agricultural University,Changchun,130118,China \\ ${ }^{2}$ Changchun University, Changchun,130000,China \\ aemail: river_zhang@163.com.
}

Key words: Principles of Computer Composition ;the three-dimensional teaching;multimedia courseware;innovative practice

\begin{abstract}
The three-dimensional Flipped Classroom teaching website can be constructed by the innovating of the theory and practice as well as the teacher's improvement of the way to teach.Combining the digitization with the heuristic teaching and in virtue of the multimedia courseware,the classroom teaching can be deepened.This article also raise the TBP teaching mode,and build a concept based on the harmonious unification of teaching researching and learning and the training of the students' creative ability.

The Flipped Classroom raised by Jon Bergmann and Jon Bergmann was start to try out in part of the U.S which got the prominent effects.However,these research did not analyze the essence of the Flipped Classroom deeply but only stopped in the way to carry out. Therefore,Professor Robert Talbert took some experiments during his teaching time and has got good effects. He has summarized the teaching model of the Flipped Classroom according to the several-year experience.Although the model summarized the main process,it ignored the other important facts which can influence the Flipped Classroom.Thus,the Flipped Classroom need to be improved further especially in the lessons of information technology.

When referring to the construction of the lessons' innovation, the teachers are meant to pay attention to how to impart the knowledge to students based on mastering the theoretical lessons as the 《Principles of Computer Composition》is a professional and less-well understood course. Traditional ways for teaching mainly focus on the teachers, and the students have to take lessons passively.As the less teaching period, the stronger theoretical property ,the wider scope of knowledge,the more contents and the faster speed of updating of the 《Principles of Computer Composition》 increase the difficulty of teachers and students,how to realize the harmonious unification between teaching and learning becomes to be a difficulty for all the educators.The authors has accumulated some experience during the eight-year teaching and practicing.Here are several parts which can be innovated in the lesson ${ }^{[1]}$.As the picture 1 shows.
\end{abstract}




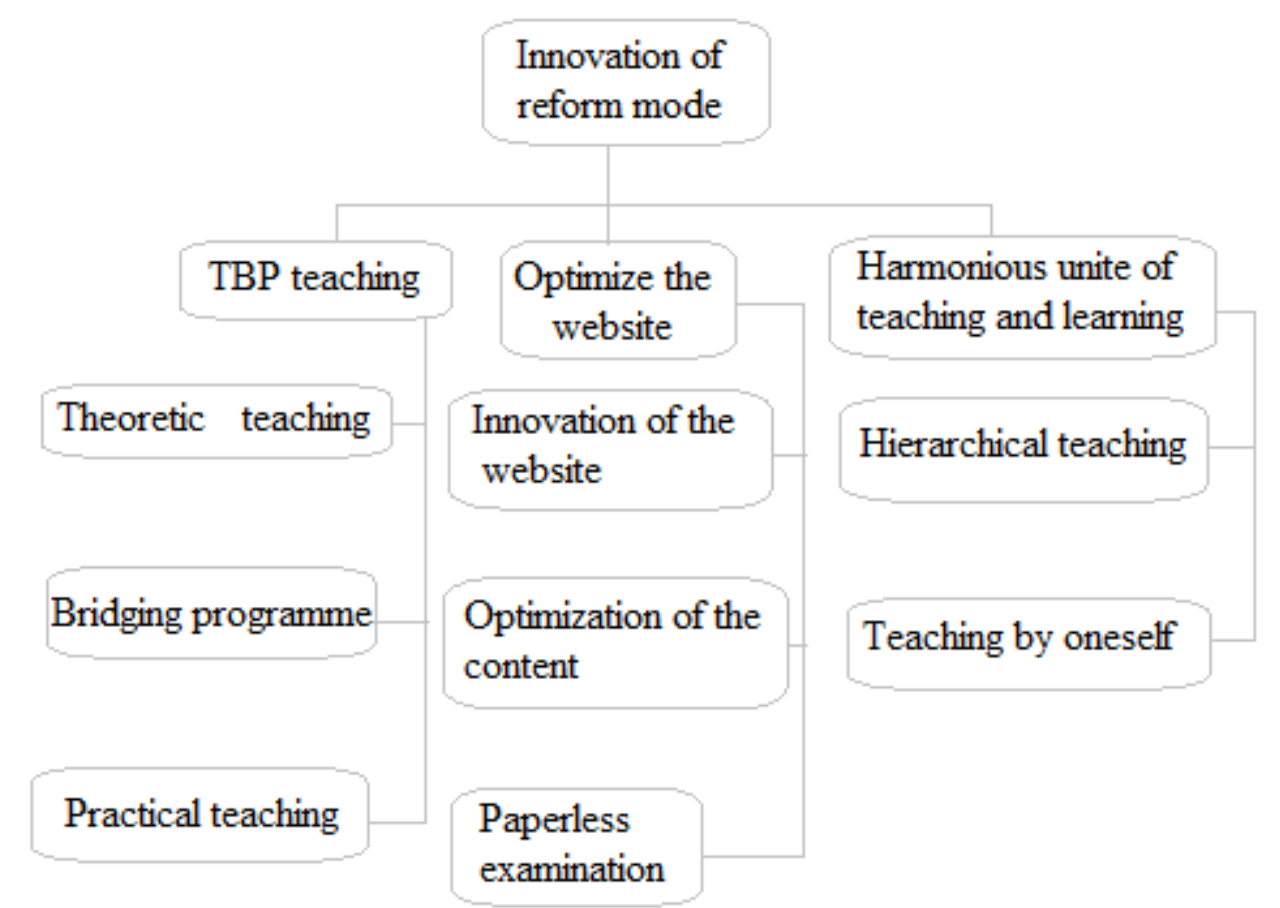

Picture 1 the structure of the innovation mode

\section{The innovation application of TBP teaching mode}

The TBP teaching mode was raised according to the three-class theory.To build the Community of Learners,innovate the teaching mode,improve the quality and effect of lessons,the theory according to the require of teaching was put forward which has three parts inside including Theoretic teaching,Bridging program and Practical teaching. As an effective teaching mode,TBP can increase the interest of learning,train the skill of students,show the aim of education and has wide application foreground in the lesson teaching.

The updating of the theoretical measures

As the content of lesson has few interest itself,students can hardly understand after learning and even feel noting valuable during the study.Thus,this situation tend the teachers to get full use of the measures to make the lesson more active.The multimedia courseware was used as an accessory way. However,the courseware often ignores the connection of the knowledge with only good visual effects, what's worse,some only copy the traditional handwriting or the teaching line and the teachers show them orderly.This situation comes out and some students say the learning effects of the multimedia is less than before,so the atmosphere is more boring.As the multimedia courseware can bring students more characters pictures and videos,it can take strong shock intuitively.

1.1 The innovative research in bridging program repetition.

As the study for Assembly Language and Principle of Micro-computer is linked to the composition of the computer and the working principles,in one hand,some knowledge will be taught repetitively and the other hand there will be more difficulty for the students to understand.Therefore,to improve the importance of the Assembly Language and Principle of Micro-computer and increase the level to understand and the ability to use,the three courses can be combined together ${ }^{[2]}$.

1.2 The practice oriented and the practice teaching reformed.

Firstly,operational ability especially the hardware is always a soft spot in teaching as many ideas are linked to the software and hardware.If they are not linked,the unrealistic feeling would come out.Practice teaching is not only a way to teach the professional knowledge,it is also a carrier rarely in the quality-oriented education, so we can make the confirmatory teaching become the project for themselves.Students should consult some information by following the teacher and are requested to get the correct location of the chip in the experimental box and explain the data lines.By this way,students can build their ability to look up the foreign materials and improve the condition 
which they prefer the software to hardware in most students.

Secondly,teachers can arrange the exhibition of the latest accessories and the assembling of the whole computer to avoid the separation between the teaching and reality aiming at the case they did not know what the CPU and RAM is.Students should take some experiments in the teaching network ahead of the schedule and master the ideas and build a complete model machine with the combination of software and hardware in the period of course design,

Thirdly,the carry out of the innovative practice can train the innovative idea and ability to think and solve the problems alone, what's more it can help find some students who has great interest and ability of the composition of computer software and hardware.The students can explore and solve various tests, control of computer and some other ways and thoughts in the realistic application combined the interface and software technology based on the computer hardware.Some can join in the program design based on the teachers' scientific research topic who have better comprehensive ability in software design.Therefore,teachers can not only afford the student a practical stage,but can let them join in the research and finally the teaching can be driven and promoted. . ${ }^{[3]}$

\section{To innovate the three-dimensional teaching website and realize the Flipped Classroom based on the campus network.}

Innovation in teaching website.

As the 《Principles of Computer Composition》 is constructed the provincial excellent course and in the efforts of becoming the provincial boutique course,if all the multimedia teaching measures can be further normalized,refined,structured and organized on the basis of the existing lesson network by using the campus network of other schools and can develop a more complete functions network,it will be more convenient for students to preview and review and can remove the initiative to study passively.The teaching website can realize the paperless and automatic management and finally reach the system of paperless examination. ${ }^{[4-6]}$.

Optimize the network teaching substance

To make teachers and students be good friends after school and discuss the relevant problems by setting up the teachers mailbox and forum,the new type of network has great advantage in simple system,good extension ability,strong function and convenience for cross-region.In the campus network,students can proceed the online testing and experiments and provide the relevant datum.At the same time,it provide extracurricular coaching column to help the students preparing for the postgraduate entrance exam to collect the latest news and questions.Therefore,a kind of good all-round three-dimensional atmosphere for each level of students can be reached.

To realize the flipped teaching mode.

Explore the practice in the flipped classroom teaching mode can confirm the feasibility of the new way to teach and get knowledge of the advantage and disadvantages in order to summarize the tips during the implementation and promote the use in the normal colleges and universities.The confirmation research and specific idea of the 《Principles of Computer Composition》about the Flipped classroom shows as below.(Picture 2$)^{[7-9]}$ 


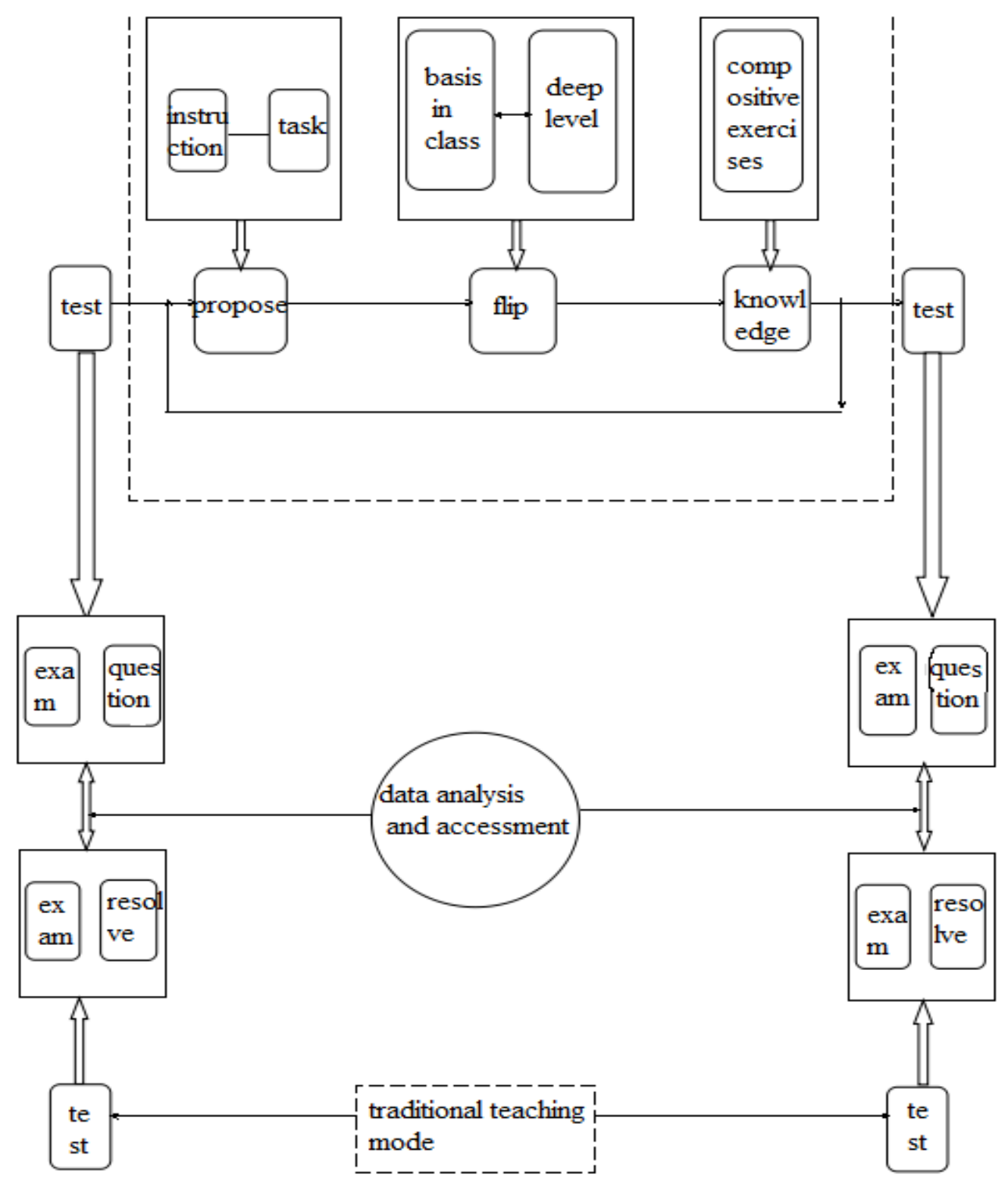

Picture 2 research structure chart of the Flipped classroom.

Organize the Flipped Classroom teaching.

First,teachers should cultivate the ability of learning themselves,sense of helping and coordinating,make sure that each learner have proficiency in every section in the network teaching system to ensure the independent study goes well.Second,to motivate the inner motivation of learners,the questions before the task should be set aiming to encourage them to study with the questions. Third,learners may plan their study according to the notes the teachers set in the system,and solve the teachers' questions by themselves.During the class,the discusses and reports,the solutions of the tasks can help to encourage the students to query and finally get knowledge of them.Last,irregular periodical tests can be taken to master the students study status and the opinion to the Flipped Classroom.

Analyze the measurement data.

Analyze the correlation comparison and difference of the questionnaire and the scores of students to confirm the learning efforts in the Flipped Classroom and the change of their abilities to learn alone and coordinate and thereby,we can explore the feasibility and limitation of the teaching mode in information technological courses,realize the real reform innovation focus on the students 
with the panel discussion and some other ways.

\section{Harmony between the teachers and students.}

The level-division interesting teaching principles.

Adopt the basic principle of seeking truth from facts,step by step,facing up the differences,distinguishing treatment and develop the features in carrying out the teaching method.Teachers should know and understand the students well,and analyze the current situation of themselves objectively.In choosing the level of teaching ,ensure to give them detailed guidance and develop their potential and help them to know their strong and weak points in order to know them goals. What's more,teachers can set different interactive games according to different students,for example: one student stand out and show a professional word by the projector, another student come to explain it or do it through an experiment.By this way,students can get the idea indirectly with joy.To inspire their passive motivation and behaviors, we should increase their interests ,curiosity and motivation and be good at finding their points of progress.

To encourage them to join in the classroom teaching,teachers can communicate with students by sending e-mail and get the extracurricular circumstance of their study ,at the same time listen to the advice given by them about the lesson. Teachers can also gather the better students,by this way,the students could join in making the courseware which can bring the interesting dynamic effects by the software technology they have mastered.Finally,the agreement would be reached between teachers and students of teaching and learning.

Innovation in the teaching way for teachers.

2.1.As Confucius said,One should be fond of learning and not feel ashamed to ask and learn of his inferiors.To stand on the platform and be praised by students,except for the basic qualities a teacher should have,we need to learn from other experienced teachers and listen to their lectures to summarize the method and update the knowledge structure to be accepted by more students.

2.2.Take the combination of the heuristic method and visualization method to improve the initiative enthusiasm and curiosity.The heuristic method is a method for students to deepen what they have learned and improve their ability of analyzing and solving problems. The visualization method is a way for teachers to have an analogy with the unintelligible ideas,professional terms and some working principles of the chips to some simple examples in our daily life.

For example,when we explain the working principles of CPU,we can compare the reality assembly line with the inner work.The assembly line was put into use in 484 chip by Intel firstly whose working mode is just like the distribution line in the industry production.There are 5-6 different electric units to form a line of command processor,and then an X86 command will be divided by 5-6 steps and execute the units respectively and so that the CPU can finish a circle and the route of the CPU calculates will improve.However,the precondition of the combination orders our teachers to prepare lessons seriously and to express clearly and fluently so the thought of students can follow and transit by the teacher. ${ }^{[10]}$

In a word,it is difficult to innovate the method of the course, Long as the way is I will keep on searching above and below.It is hard but honorable for the teachers to do research.As a teacher,it's our duty to cultivate the talents who have high quality and ability for our country with the flexible and advanced teaching method.

\section{Acknowledgement}

In this paper, the research was sponsored by 1 . the Key Research Subject of College Education Teaching Reform of Jilin Province in 2015.(The application research of the Internet teaching mode of the Flipped Classroom in Agricultural Universities--taking the information technological courses as example.)

2.Planned Research Topics in Jilin Province (Research of the building of Regular Institutions in Higher Learning and High-level Faculty.)

3. The Key Research Subject of Education and Teaching in Jilin Agricultural 
University,2015.(Research the "Double Teachers" Teaching Staff Construction Based on the MOOCS Mode in Higher Universities.)

4.the Key Research Subject of College Education Teaching Reform of Jilin Province in 2015.(The research and practice of the normal teachers Performance Management based on the Balanced Score Card in High Universities.)

\section{References}

[1] Li Li. Research of Employment as the Guidance of the Secondary Vocational Computer Teaching Model [J]. Intelligence. 2016(04)

[2] Hongmei Ye. Research Based on the Skilled Personnel Training of Computer Teaching Mode[J]. Information and computer . 2016(02)

[3]Yan Huang. Guided by Employment of Higher Vocational Computer Teaching Mode Analysis[J]. Technology Outlook. 2015(34)

[4] Hongyuan Tang. Analysis about Higher Vocational Computer Teaching Mode of Employment Oriented [J]. Shandong Industrial Technology. 2015(10)

[5] Qian Zhang,Jian Yang. Research In order to Promote University Students' Employment as the Guidance of the Computer Teaching Model [J]. Computer CD Software and Application. 2014(01)

[6] Yaling Tang. Exploration Under the Current Education System of Computer Teaching Mode of [J]. Chinese Management Informationization. 2014(09)

[7] Hailin Fang. Teaching Mode Guided by Social Needs of the Secondary Vocational Computer [J].Electronic World. 2014(02)

[8] Dan Liang. Teaching Mode Based on the Social Demand of Higher Vocational Computer[J]. Information and Computer. 2014(05)

[9] Nanyu Jiang.Teaching Mode Reform Based on Employment Oriented Strategy Analysis of College Computer [J]. Information and Communication. 2014(10)

[10] Baojun Liu. Computer Teaching Mode Based on Analysis of Modern Education Technology [J]. Heilongjiang science and technology information. 2013(35) 